\title{
Improved Incentive Pricing Wireless Multi-service Single Link with Bandwidth Attribute
}

\author{
Nael Hussein ${ }^{1}$, Kamaruzzaman Seman ${ }^{2}$, Fitri Maya Puspita ${ }^{3}$, Khairi Abdulrahim ${ }^{4}$, Mus'ab Sahrim ${ }^{5}$ \\ Faculty of Engineering and Built Environment, Universiti Sains Islam Malaysia, Nilai, 71800 Negeri Sembilan, Malaysia $a^{1,2,4,5}$ \\ Sriwijaya University, Indralaya, South Sumatra, 30662, Indonesia ${ }^{3}$
}

\begin{abstract}
Several objectives that service providers have to achieve are to determine the increase or decrease in the price change due to the change in service quality and the amount of service quality value. Multi-service wireless Internet pricing schemes that apply the quality of the bandwidth advantage are designed to take into account the need of ISPs to provide highquality services to users and increase their revenue, considering the limited bandwidth of the resources. The modified model is an improvement of the original model by adding variables and parameters to the multiple service network model by specifying the base price for QoS (alpha) and premium quality ( $\beta$ ) as variables, parameters, and service class load factor, Pregnancy basis factor and differentiation factor. The models are solved by the program Lingo 18.0 to get the best solution. The results prove that the modified model is the best and yields the best profit for the service provider when the cost of all changes in quality of service is increased and the variable $\alpha$ and $\beta$ is set as constant or variable.
\end{abstract}

Keywords-Optimal solution; multi service network; wireless pricing scheme; bandwidth QoS attribute

\section{INTRODUCTION}

The Internet plays a big role in developing the economy and is seen as an important catalyst for restructuring business activities [1]. The volume of demand on the Internet has increased, especially with the emergence of the IOT and its multiple uses that require an Internet connection to display the results of the sensors [2]. Quality of service in networks is defined as the mechanisms that allow distinguishing network services based on their unique service requirements [3].

The DiffServ and IntServ architectures allow the implementation and differentiation of QoS to different specifications on a given network [4]. The pricing works to regulate the use of the Internet by providing appropriate pricing that is equivalent to the quality of service, which is reflected in improving network performance and avoiding congestion [5]. Internet service providers should provide an appropriate internet pricing mechanism and a better and different quality of service [6]. The best way to prevent network congestion and distinguish its services is through usage-based pricing schemes [7]. The author in [8] Improved the reverse charging scheme of a multi-service connection in a wireless network with an bit error rate feature, in addition take in to account basic cost ,quality of service, and reached optimal profit when adjusting the basic costs as fix and quality as variable. Designed the reverse charging model within a multi-link network in the wireless network, based on the end to end feature [9]. The Internet service provider must take into account the provision of prices, the price is affected by quality and variable depending on the quality of the service [10].

Avoiding congestion requires studying consumer behavior, knowing peak times, and working on balancing loads in multiservice networks to avoid congestion [11]. Internet service providers suffer during peak usage times from congestion, and therefore there is a need for an appropriate pricing scheme that seeks to control usage at peak times to prevent network collapse and encourage consumers to rationalize their consumption during peak times [12].

Designed a model to price the Internet in multiple links depending on the incentive mechanism so that the service provider chooses to either recover the cost or promote a particular service [13]. The author in [14] proposed a mathematical model of the Paris metro pricing Scheme for charging the packet networks, which is based on dividing the networks into sub-networks or classes, and fees are imposed on their customers at different prices.

The optimal solution is determined by the basic price, either it is a fixed price for the purpose of recovering the cost or the price is variable for the purpose of competition, determining the quality premium and the level of service quality to enable the user to choose the categories [15]. The author in [16] improved the Bundle Pricing model in the wireless internet model on the multiple QoS network by integrating the quasi-linear utility function with the bundle problem and the consumer problem. And they concluded that the best solution is in the feature of Bit Error Rate on the flat fee and two-part tariff internet pricing scheme.

The author in [17] discussed a wireless pricing scheme on a multi-category single link models with the bandwidth attribute and taking into account the addition of the base value of the price and the variable of quality premium. The author in [18] explained a wireless pricing scheme on a multi-category model with the Bit Error Rate (BER) QoS attribute and taking into account the addition of the base value of the price and the variable of quality premium. In [19], the author discussed improving the wireless internet pricing scheme using different features of the multiple QoS network.

The authors in [20], [21] explained that the Internet pricing scheme is based on three strategies, namely, the flat fee, twopart tariff, and usage based. We note that the topic of Internet pricing in wireless networks has been covered recently in several papers. Optimization needs prior study about understanding user behavior and when demand will rise, as 
well as knowing what kind of service is badly needed. Thus, by determining the basic demand factor in the network and the demand factor for users, as well as knowing the magnitude of differentiation between service classes and the demand for them by users, this will provide a more accurate and more profitable pricing scheme for the service provider. In this paper [22], we present multi-service wireless single network incentive pricing scheme based on the bandwidth attribute.

This paper is organized as follows: the research methodology and case study used are described in the second section. The third section explains the analysis and comparison of the results of the different models. Finally, the main conclusions are summarized in the conclusion section. Pricing models will be solved to reach the optimal solution using the Lingo program.18, the data used to test the model consists of three types of traffic classes, which are mail and files and an IP camera, obtained from a local server. The results will be compared between our pricing scheme in wireless network with bandwidth attribute , the original model [22] and a model that has been developed in wireless network with the attribute of bandwidth [17], all results will be shown in the tables presented in the results section.

\section{RESEARCH METHOD}

In [22], we work to improve the model presented by [11] in the pricing of wireless multi-service Internet with bandwidth QOS attribute by looking at the model as an optimization problem that can be solved in the optimization tool using Lingo 18 , which simulates formulas and search results.

In this paper, we contribute to the QOS multiservice wireless internet pricing model, and provide better results than model [22], [17].

The idea originated mainly from [3], [11], [22] the goal is to improve wireless Internet networks for a single link. The model consists of the objective function that will be maximized and the constraints of the model that form the framework that cannot be crossed during the solution and that consists of limits and controls.

We seek to get the best solution that represents the best profit for the provider by transforming the problem of pricing the Internet in the networks of one link and multiple services into an improvement model and trying to solve it to get the best solution that will help explain the problems that include pricing of services, the load in the network with its multiple services and the volume of Bandwidth required by the user. The goal of this optimization is to maximize the gain based on the load; parameter in the multicast, the base load factor and the diversity factor, bandwidth.

\section{A. Original Models using Bandwidth Qos Attribute}

In this section, we explain the meaning of the variables contained in the original model.

$\mathrm{PR}_{i k}$ : The cost to connect to the QoS provided.

$\mathrm{PQ} Q_{i k}$ : Changes in the cost of all the changes QoS.

$\mathrm{X}$ : Amount of increase or decrease in the value of QoS.

$Q_{P i k}$ : Nominal value attribute QoS in the network operator.
$\mathrm{PB}_{i k}$ : The basic cost for a connection with the service I and links $\mathrm{k}$.

Lx : Linearity factor

$T_{l}:$ Traffic load

$a_{\mathrm{ik}}$ : linear price factor for each service (i) and links(j).

a : Linear parameter set.

B : Linear parameter set.

$\mathrm{F}, \mathrm{g}, \mathrm{h}$ : A predetermined minimum value for a service provider.

$a_{\mathrm{ik}}$ : The maximum value that has been set for the service provider.

$T_{l}$ : The minimum amount of load traffic that is allowed.

$T_{\mathrm{ik}}$ : The maximum amount of traffic goods that is

allowed.

The Wireless bandwidth schema is divided by the original form into four sections depending on the value of $\mathrm{X}$. the objective function as follows:

$M A X R=\sum_{k=1}^{r} \sum_{i=1}^{s}\left(\mathrm{PR}_{i k} \pm P Q_{i k}\right)$

Subject to:

$\mathrm{P} Q_{11}=(1 \pm \mathrm{x} / 2000) \mathrm{PB}_{11} L_{x}$

$\mathrm{P} Q_{12}=(1 \pm \mathrm{x} / 2000) \mathrm{PB}_{12} L_{x}$

$\mathrm{PQ}_{21}=(1 \pm \mathrm{x} / 2000) \mathrm{PB}_{21} L_{x}$

$\mathrm{PQ}_{22}=(1 \pm \mathrm{x} / 2000) \mathrm{PB}_{22} L_{x}$

$\mathrm{P} B_{11}=a_{11}\left(\mathrm{e}-e^{-x B}\right) T_{l} / 100$

$\mathrm{P} B_{12}=a_{11}\left(\mathrm{e}-e^{-x B}\right) T_{l} / 100$

$\mathrm{P} B_{21}=a_{21}\left(\mathrm{e}-e^{-x B}\right) T_{l} / 100$

$\mathrm{P} B_{22}=a_{22}\left(\mathrm{e}-e^{-x B}\right) T_{l} / 100$

$L_{X}=\left(\mathrm{e}-e^{-x B}\right)$

$0.05 \leq a_{11} \leq 0.15$

$0.06 \leq a_{12} \leq 0.14$

$0.07 \leq a_{21} \leq 0.13$

$0.08 \leq a_{22} \leq 0.12$

$50 \leq T_{l} \leq 1000$

$0 \leq x \leq 1$

$0.8 \leq \mathrm{B} \leq 1.07$

$a=1$

\section{B. Modified Models}

The model was developed to improve its results by combining a multi-service wireless network model and adding parameters and variables, where the basic price $(\alpha)$ and premium quality $(\beta)$ for each service category will be determined in addition to the load factor and the variance 
factor. The model, variables, and decision parameters are formulated within the constraints and determinants of the network.

We improve models by four cases:

1) $\alpha$ and $\beta$ constants.

2) $\alpha$ constants and $\beta$ variable.

3) $\alpha$ and $\beta$ variables.

4) $\alpha$ variables and $\beta$ constants.

Parameters used in the modified models are as follows:

i: priority of the service.

$\mathrm{C}$ : bandwidth capacity of link K.

$L_{\text {base }}$ : base load factor for the network.

$Z_{\mathrm{ik}}$ : requested bandwidth in class $\mathrm{I}$ in link $\mathrm{k}$.

$R_{\mathrm{ik}}$ : price service class I at link k.

$p_{\mathrm{ik}}$ : load factor for service class I at link k.

$L_{\mathrm{ik}}$ : load of service class I at link $\mathrm{k}$.

$I_{\mathrm{i}}$ : Quality of service index $i$.

$a_{\mathrm{ik}}$ : price service I in link $k$.

$m_{\mathrm{I}}$ : Minimum QoS for service $i$.

$I t:$ The minimum premium for the service $i$.

$b_{\mathrm{i}}$ : The maximum premium for the service $\mathrm{i}$.

$y$ : The minimum base price for service $i$.

$\mathrm{z}$ : The maximum base price for service $\mathrm{i}$.

5) Modified model case $\alpha$ and $\beta$ constants: Wireless pricing schemes in the first case, the objective function is as follows:

$M A X R=\sum_{k=1}^{r} \sum_{i=1}^{S}\left(\mathrm{PR}_{i k} \pm P Q_{i k}\right)+\left(a+\beta . I_{i}\right)+\mathrm{R}_{i k} *$ $\left.\mathrm{Z}_{i k} * \mathrm{P}_{i k}\right)$

Subject to:

$$
\begin{aligned}
& \mathrm{PQ}_{11}=\left(1 \pm \frac{\mathrm{x}}{2000}\right) \mathrm{PB}_{11} L_{x} \\
& \mathrm{P} Q_{21}=\left(1 \pm \frac{\mathrm{x}}{2000}\right) \mathrm{PB}_{21} L_{x} \\
& \mathrm{P} Q_{31}=\left(1 \pm \frac{\mathrm{x}}{2000}\right) \mathrm{PB}_{31} L_{x} \\
& P B_{11}=a_{11}\left(\mathrm{e}-e^{-x B}\right) T_{l} / 100 \\
& P B_{21}=a_{21}\left(\mathrm{e}-e^{-x B}\right) T_{l} / 100 \\
& \mathrm{P} B_{31}=a_{31}\left(\mathrm{e}-e^{-x B}\right) T_{l} / 100 \\
& \mathrm{P} L_{X}=\left(\mathrm{e}-e^{-x B}\right) \\
& 0.05 \leq a_{11} \leq 0.15 \\
& 0.06 \leq a_{24} \leq 0.14 \\
& 0.07 \leq a_{31} \leq 0.13
\end{aligned}
$$

$50 \leq T_{l} \leq 1000$

$0 \leq \mathrm{x} \leq 1$

$0.8 \leq \mathrm{B} \leq 1.07$

$a=1$

$P 11=\left(\frac{1-L_{\text {base }}}{1-L_{11}}\right)^{n}$

$P 21=\left(\frac{1-L_{\text {base }}}{1-L_{11}}\right)^{n}$

$P 31=\left(\frac{1-L_{\text {base }}}{1-L_{11}}\right)^{n}$

L1 $1<1$

L21 1

L31 < 1

$0 \leq$ Lbase $\leq 1$

$\mathrm{n}>1$

$\mathrm{L} 11+\mathrm{L} 21+\mathrm{L} 31=1$

$\mathrm{Z}_{11}<=\mathrm{C}$

$\mathrm{Z}_{21}<=\mathrm{C}$

$\mathrm{Z}_{31}<=\mathrm{C}$

$I_{1} P_{11} \leq a_{11}$

$I_{2} P_{21} \leq a_{21}$

$I_{3} P_{31} \leq a_{31}$

$I_{1} P_{11}+I_{2} P_{21}+I_{3} P_{31} \leq \mathrm{C}$

$a_{11}+a_{21}+a_{31}=1$

$0 \leq a_{11} \leq 1$

$0 \leq a_{21} \leq 1$

$0 \leq a_{31} \leq 1$

$0.01 \leq I_{1} \leq 1$

$0.01 \leq I_{2} \leq 1$

$0.01 \leq I_{3} \leq 1$

By modifying the index of quality of services $\left(I_{i}\right)$ we obtain

$I_{i}=I_{i-1}$

$I_{2-} I_{1}=0$

$I_{3-} I_{2}=0$

6) Modified model case $\alpha$ constants and $\beta$ variable: Wireless pricing schemes in the second case, the objective function is as follows:

$M A X R=\sum_{k=1}^{r} \sum_{i=1}^{s}\left(\mathrm{PR}_{i k} \pm P Q_{i k}\right)+\left(a+\beta_{i} . I_{i}\right)+\mathrm{R}_{i k} * \mathrm{Z}_{i k} *$ $\left.\mathrm{P}_{i k}\right)$

With subject to equation: (2)-(33), as well as the added constraints. 
$\beta_{2} I_{2} \geq \beta_{1} I_{1}$

$\beta_{3} I_{3} \geq \beta_{2} I_{2}$

$0.01 \leq \beta_{1} \leq 0.5$

$0.01 \leq \beta_{2} \leq 0.5$

$0.01 \leq \beta_{3} \leq 0.5$

$\beta_{1}=\beta_{1-1}$ by modifying the service quality index, I (Ii) and the premium quality of service then added constraints

$\beta_{2}-\beta_{1}=0$

$\beta_{3}-\beta_{2}=0$

7) Modified model case $\alpha$ and $\beta$ variables: Wireless pricing schemes in third case, the objective function is as follow:

$M A X R=\sum_{k=1}^{r} \sum_{i=1}^{S}\left(\mathrm{PR}_{i k} \pm P Q_{i k}\right)+\left(a_{i}+\beta_{i} \cdot I_{i}\right)+\mathrm{R}_{i k} * \mathrm{Z}_{i k} *$ $\left.\mathrm{P}_{i k}\right)$

With subject to equation: (2)-(33) and equation. (46) - (50), as well as the added constraints

$a_{2}+\beta_{2} I_{2} \geq a_{1}+\beta_{1} I_{1}$

$a_{3}+\beta_{3} I_{3} \geq a_{2}+\beta_{2} I_{2}$

$0 \leq a_{1} \leq 1$

$0 \leq a_{2} \leq 1$

$0 \leq a_{3} \leq 1$

$a_{\mathrm{I}}-=a_{1-1}$ by modifying the service quality index $\mathrm{i}\left(l_{1}\right)$ and set a base price and premium service and added constraints :

$a_{2}-a_{1}=0$

$a_{3}-a_{2}=0$

8) Modified model case $\alpha$ variables and $B$ constants: Wireless pricing schemes in fourth case, the objective function is as follow:

$M A X R=\sum_{k=1}^{r} \sum_{i=1}^{s}\left(\mathrm{PR}_{i k} \pm \mathrm{P} Q_{i k}\right)+\left(a_{i}+\beta . I_{i}\right)+\mathrm{R}_{i k} *$

$\left.\mathrm{Z}_{i k} * \mathrm{P}_{i k}\right)$

with subject to equation. (2)- (32), (34)-(42). (54)-(56), with added constraints as follows

$a_{2}+I_{2} \geq a_{1}+I_{1}$

$a_{3}+I_{3} \geq a_{2}+I_{2}$

\section{RESULT AND DISCUSSION}

In this section, the results for the four cases are presented separately. The solution consists of three tables. Table I shows the optimal solution for the paper [17] and Table II shows the optimal solution for the modified model [23], which is the value of the objective function. The Table III represents the value of the variables in the modified model, Results Original Model:

- $\alpha$ and $\beta$ constants in bandwidth QoS
TABLE I. OPTIMAL SOLUTION FOR [17] MODEL FOR $a$ AND $\beta$ CONSTANTS IN BANDWIDTH QOS

\begin{tabular}{|l|l|l|l|l|}
\hline Var & $\begin{array}{l}\text { pqij } \\
\text { increase } \boldsymbol{x} \\
\text { increase }\end{array}$ & $\begin{array}{l}\text { pqij } \\
\text { increase } \\
\boldsymbol{x} \text { decrease }\end{array}$ & $\begin{array}{l}\text { Pqij } \\
\text { decrease } \boldsymbol{x} \\
\text { increase }\end{array}$ & $\begin{array}{l}\text { Pqij } \\
\text { decrease } \boldsymbol{x} \\
\text { decrease }\end{array}$ \\
\hline Model Class & INLP & INLP & INLP & INLP \\
\hline State & Local Opt & Local Opt & Local Opt & Local Opt \\
\hline Objective & 125.681 & 125.625 & 67.7576 & 67.7576 \\
\hline Infeasibility & 0 & 0 & 0 & 0 \\
\hline Iter & 13 & 13 & 45 & 45 \\
\hline GMU & $32 \mathrm{~K}$ & $32 \mathrm{~K}$ & $32 \mathrm{~K}$ & $32 \mathrm{~K}$ \\
\hline ER & 0 & 0 & 0 & 0 \\
\hline
\end{tabular}

TABLE II. OPTIMAL SOLUTION FOR MODELS FOR $a$ AND $\beta$ CONSTANTS IN BANDWIDTH QOS

\begin{tabular}{|l|l|l|l|l|}
\hline Var & $\begin{array}{l}\text { pqij } \\
\text { increase } \boldsymbol{x} \\
\text { increase }\end{array}$ & $\begin{array}{l}\text { pqij increase } \\
\boldsymbol{x} \text { decrease }\end{array}$ & $\begin{array}{l}\text { Pqij } \\
\text { decrease } \boldsymbol{x} \\
\text { increase }\end{array}$ & $\begin{array}{l}\text { Pqij } \\
\text { decrease } \boldsymbol{x} \\
\text { decrease }\end{array}$ \\
\hline $\begin{array}{l}\text { Model } \\
\text { Class }\end{array}$ & NLP & NLP & NLP & NLP \\
\hline State & Local Opt & Local Opt & Local Opt & Local Opt \\
\hline Objective & 791.567 & 791.560 & 733.511 & 733.511 \\
\hline Infeasibility & 0 & 0 & 0 & 0 \\
\hline Iter & 14 & 14 & 14 & 14 \\
\hline GMU & 41 & 41 & 41 & 41 \\
\hline ER & 0 & 0 & 0 & 0 \\
\hline
\end{tabular}

Based on the objective function (19) with equation, (20) to (59), the optimal solution in each case on bandwidth QoS attributes solved using LINGO 18.0 are presented in Table II and Table III.

Based on Tables III and IV, the value achieved the most optimal results in the first case is equal to 791.567. These results obtained by 13 iterations of the infeasibility of 0 . Generated Memory Used (GMU) that is $32 \mathrm{~K}$ and Elapsed Runtime I is 0 seconds.

We note the difference between the model [17] and the modified model, where the difference is clear in the value of the objective function between the four cases in each model Thus, by comparing the best value of the objective function in the model [17] in the case of fixed alpha and beta, it is equal to 125.681, while in the modified model it is equal to 791.567 .

- $\alpha$ constant and $\beta$ variable in Bandwidth Qos

Based on the objective function (60) and the equations from (2) to (32) and (61) to (65): The optimal solution is summarized in Tables V and VI for each case of the bandwidth features that were solved using Lingo 18.

From Tables IV and V, we notice that the first case achieved the best results compared to the rest of the cases, where the objective is 791.434 , where the results are reached after 14 repetitions. Zero invisibility, 43 memory usage, and zero runtime. The results of the values of the first and second cases are similar, while the results of the third and fourth cases are identical. By comparing the objective value between the 
two models, we see that our model outperforms the previous model by about 665.753 .

TABLE III. OPTIMAL SOLUTION FOR MODEL FOR $a$ AND $\beta$ CONSTANTS IN BANDWIDTH QOS

\begin{tabular}{|l|l|l|l|l|}
\hline Var & $\begin{array}{l}\text { pqij } \\
\text { increase } \boldsymbol{x} \\
\text { increase }\end{array}$ & $\begin{array}{l}\text { pqij increase } \\
\boldsymbol{x} \text { decrease }\end{array}$ & $\begin{array}{l}\text { Pqij decrease } \\
\boldsymbol{x} \\
\text { increase }\end{array}$ & $\begin{array}{l}\text { Pqij decrease } \\
\boldsymbol{x} \\
\text { decrease }\end{array}$ \\
\hline PQ11 & 8.487065 & 8.458654 & 0.2214369 & 0.2214369 \\
\hline PQ21 & 7.921260 & 7.894743 & 0.2066745 & 0.2066745 \\
\hline PQ31 & 40.17211 & 40.03763 & 1.048135 & 1.048135 \\
\hline X & 1 & 1 & 0 & 0 \\
\hline PB11 & 3.562910 & 3.562910 & 0.042957 & 0.042957 \\
\hline PB21 & 3.325383 & 3.325383 & 0.060139 & 0.060139 \\
\hline PB31 & 16.86444 & 16.86444 & 0.068731 & 0.068731 \\
\hline PR11 & 0.5 & 0.5 & 0.5 & 0.5 \\
\hline PR21 & 0.6 & 0.6 & 0.6 & 0.6 \\
\hline PR31 & 0.7 & 0.7 & 0.7 & 0.7 \\
\hline a11 & 0.15 & 0.15 & 0.05 & 0.05 \\
\hline a21 & 0.14 & 0.14 & 0.06 & 0.06 \\
\hline a31 & 0.71 & 0.71 & 0.07 & 0.07 \\
\hline Lx & 2.375273 & 2.375273 & 1.718282 & 1.71828 \\
\hline T1 & 1000 & 1000 & 50 & 50 \\
\hline a & 1 & 1 & 1 & 1 \\
\hline B & 1.07 & 1.07 & 0.8 & 0.8 \\
\hline I1 & 0.2983710 & 0.2983710 & 0.2983710 & 0.2983710 \\
\hline I2 & 0.2983710 & 0.2983710 & 0.2983710 & 0.2983710 \\
\hline I3 & 0.2983710 & 0.2983710 & 0.2983710 & 0.2983710 \\
\hline P11 & 0.5072075 & 0.5072075 & 0.5072075 & 0.5072075 \\
\hline P21 & 0.4717468 & 0.4717468 & 0.4717468 & 0.4717468 \\
\hline P31 & 0.4258186 & 0.4258186 & 0.4258186 & 0.4258186 \\
\hline L11 & 0,3 & 0.3 & 0.3 & 0.3 \\
\hline L21 & 0.33 & 0.33 & 0.33 & 0.33 \\
\hline L31 & 0.37 & 0.37 & 0.37 & 0.37 \\
\hline R11 & 0.00007 & 0.00007 & 0.00007 & 0.00007 \\
\hline R21 & 0.0006 & 0.0006 & 0.0006 & 0.0006 \\
\hline R31 & 0.005 & 0.005 & 0.005 & 0.005 \\
\hline & & & & \\
\hline
\end{tabular}

TABLE IV. OPTIMAL SOLUTION FOR ORIGINAL MODELS FOR $a$ CONSTANT AND $\beta$ VARIABLE IN BANDWIDTH QOS

\begin{tabular}{|l|l|l|l|l|}
\hline Var & $\begin{array}{l}\text { pqij } \\
\text { increase } \boldsymbol{x} \\
\text { increase }\end{array}$ & $\begin{array}{l}\text { pqij } \\
\text { increase } \\
\boldsymbol{x} \text { decrease }\end{array}$ & $\begin{array}{l}\text { Pqij } \\
\text { decrease } \boldsymbol{x} \\
\text { increase }\end{array}$ & $\begin{array}{l}\text { Pqij } \\
\text { decrease } \boldsymbol{x} \\
\text { decrease }\end{array}$ \\
\hline Model Class & INLP & INLP & INLP & INLP \\
\hline State & Local Opt & Local Opt & Local Opt & Local Opt \\
\hline Objective & 125.681 & 125.625 & 67.7576 & 67.7576 \\
\hline Infeasibility & 0.015 & 0.011 & 0 & 0 \\
\hline Iter & 24 & 24 & 13 & 13 \\
\hline GMU & $34 \mathrm{~K}$ & $34 \mathrm{~K}$ & $34 \mathrm{~K}$ & $34 \mathrm{~K}$ \\
\hline ER & Os & Os & Os & Os \\
\hline
\end{tabular}

TABLE V. OPtIMAL SOLUTION FOR MODELS FOR $\alpha$ CONSTANT AND $\beta$ VARIABLE IN BANDWIDTH QOS

\begin{tabular}{|l|l|l|l|l|}
\hline Var & $\begin{array}{l}\text { pqij } \\
\text { increase } \boldsymbol{x} \\
\text { increase }\end{array}$ & $\begin{array}{l}\text { pqij } \\
\text { increase } \\
\boldsymbol{x} \text { decrease }\end{array}$ & $\begin{array}{l}\text { Pqij } \\
\text { decrease } \boldsymbol{x} \\
\text { increase }\end{array}$ & $\begin{array}{l}\text { Pqij } \\
\text { decrease } \boldsymbol{x} \\
\text { decrease }\end{array}$ \\
\hline Model Class & NLP & NLP & NLP & NLP \\
\hline State & Local Opt & Local Opt & Local Opt & Local Opt \\
\hline Objective & 791.434 & 791.378 & 734.563 & 733.511 \\
\hline Infeasibility & 0 & 0 & 0 & 0 \\
\hline Iter & 14 & 14 & 14 & 14 \\
\hline GMU & 43 & 43 & 43 & 43 \\
\hline ER & 0 & 0 & 0 & 0 \\
\hline
\end{tabular}

TABLE VI. VARIABLE VALUES FOR MODELS FOR $\alpha$ CONSTANT AND $\beta$ VARIABLE IN BANDWIDTH QOS

\begin{tabular}{|c|c|c|c|c|}
\hline Var & $\begin{array}{l}\text { pqij } \\
\text { increase } x \\
\text { increase }\end{array}$ & $\begin{array}{l}\text { pqij } \\
\text { increase } \\
x \text { decrease }\end{array}$ & $\begin{array}{l}\text { Pqij } \\
\text { decrease } x \\
\text { increase }\end{array}$ & $\begin{array}{l}\text { Pqij decrease } \\
x \\
\text { decrease }\end{array}$ \\
\hline PQ11 & 8.467116 & 8.458654 & 0.2214369 & 0.2214369 \\
\hline PQ21 & 7.902640 & 7.894741 & 0.2066745 & 0.2066745 \\
\hline PQ31 & 40.07769 & 40.03763 & 1.048135 & 1.048135 \\
\hline $\mathbf{X}$ & 1 & 1 & 0 & 0 \\
\hline PB11 & 3.562910 & 3.562910 & 0.1288711 & 0.1288711 \\
\hline PB21 & 3.325382 & 3.325382 & 0.1202797 & 0.1202797 \\
\hline PB31 & 16.86444 & 16.86444 & 0.6099900 & 0.6099900 \\
\hline PR11 & 0.5 & 0.5 & 0.5 & 0.5 \\
\hline PR21 & 0.6 & 0.6 & 0.6 & 0.6 \\
\hline PR31 & 0.7 & 0.7 & 0.7 & 0.7 \\
\hline a11 & 0.15 & 0.15 & 0.15 & 0.15 \\
\hline a21 & 0.14 & 0.14 & 0.14 & 0.14 \\
\hline a31 & 0.71 & 0.71 & 0.71 & 0.71 \\
\hline $\mathbf{L} x$ & 2.375273 & 2.375273 & 1.718282 & 1.71828 \\
\hline$T l$ & 1000 & 1000 & 50 & 50 \\
\hline $\mathbf{a}$ & 1 & 1 & 1 & 1 \\
\hline B & 1.07 & 1.07 & 0.8 & 0.8 \\
\hline$\beta 1$ & 0.5 & 0.5 & 0.5 & 0.5 \\
\hline$\beta 2$ & 0.5 & 0.5 & 0.5 & 0.5 \\
\hline$\beta 3$ & 0.5 & 0.5 & 0.5 & 0.5 \\
\hline I1 & 0.2983710 & 0.2983710 & 0.2983710 & 0.2983710 \\
\hline I2 & 0.2983710 & 0.2983710 & 0.2983710 & 0.2983710 \\
\hline I3 & 0.2983710 & 0.2983710 & 0.2983710 & 0.2983710 \\
\hline$\Lambda 11$ & 0,3 & 0.3 & 0.3 & 0.3 \\
\hline$\Lambda 21$ & 0.33 & 0.33 & 0.33 & 0.33 \\
\hline$\Lambda 31$ & 0.37 & 0.37 & 0.37 & 0.37 \\
\hline P11 & 0.00007 & 0.00007 & 0.00007 & 0.00007 \\
\hline P21 & 0.0006 & 0.0006 & 0.0006 & 0.0006 \\
\hline P31 & 0.005 & 0.005 & 0.005 & 0.005 \\
\hline
\end{tabular}


- $\alpha$ and $\beta$ variable in bandwidth QoS:

Based on the objective function (68) and the equations from (2) to (32) and (46) to (50) and additional constraints (60) to (66): The optimal solution is summarized in Tables VII and VIII for each case of the bandwidth features that were solved using Lingo18.

We note from Table VIII that the first case achieved the best result, I need to get the results 14 iterations and the value of the memory used is 45 . From Table IX, we notice that the values of the variables in the first and second cases are close, while in the 3 and 4 the results are identical. The first case gives the best results for the values of the variables. By comparing the objective value between the two models, we see that our model outperforms the previous model is 164.449

TABLE VII. OPTIMAL SOLUTION FOR ORIGINAL MODELS FOR $a$ AND $\beta$ VARIABLE IN BANDWIDTH QOS

\begin{tabular}{|l|l|l|l|l|}
\hline Var & $\begin{array}{l}\text { pqij } \\
\text { increase } \boldsymbol{x} \\
\text { increase }\end{array}$ & $\begin{array}{l}\text { pqij } \\
\text { increase } \\
\boldsymbol{x} \text { decrease }\end{array}$ & $\begin{array}{l}\text { Pqij } \\
\text { decrease } \boldsymbol{x} \\
\text { increase }\end{array}$ & $\begin{array}{l}\text { Pqij } \\
\text { decrease } \boldsymbol{x} \\
\text { decrease }\end{array}$ \\
\hline Model Class & INLP & INLP & INLP & INLP \\
\hline State & Local Opt & Local Opt & Local Opt & Local Opt \\
\hline Objective & 629.681 & 692.625 & 634.758 & 634.758 \\
\hline Infeasibility & 0 & 0 & $1.1 \times 10-16$ & $1.1 \times 10-16$ \\
\hline Iter & 12 & 12 & 13 & 13 \\
\hline GMU & $35 \mathrm{~K}$ & $35 \mathrm{~K}$ & $35 \mathrm{~K}$ & $35 \mathrm{~K}$ \\
\hline ER & $0 \mathrm{~s}$ & $0 \mathrm{~s}$ & $0 \mathrm{~s}$ & $0 \mathrm{~s}$ \\
\hline
\end{tabular}

TABLE VIII. OPTIMAL SOLUTIONS FOR MODELS FOR $\alpha$ AND $\beta$ VARIABLE IN BANDWIDTH QOS

\begin{tabular}{|l|l|l|l|l|}
\hline Var & $\begin{array}{l}\text { pqij } \\
\text { increase } \boldsymbol{x} \\
\text { increase }\end{array}$ & $\begin{array}{l}\text { pqij } \\
\text { increase } \\
\boldsymbol{x} \text { decrease }\end{array}$ & $\begin{array}{l}\text { Pqij } \\
\text { decrease } \boldsymbol{x} \\
\text { increase }\end{array}$ & $\begin{array}{l}\text { Pqij } \\
\text { decrease } \boldsymbol{x} \\
\text { decrease }\end{array}$ \\
\hline Model Class & NLP & NLP & NLP & NLP \\
\hline State & Local Opt & Local Opt & Local Opt & Local Opt \\
\hline Objective & 794.130 & 794.076 & 736.211 & 736.211 \\
\hline Infeasibility & 0 & 0 & 0 & 0 \\
\hline Iter & 14 & 14 & 14 & 14 \\
\hline GMU & 45 & 45 & 43 & 43 \\
\hline ER & 0 & 0 & 0 & 0 \\
\hline
\end{tabular}

TABLE IX. VARIABLE VALUES FOR MODELS FOR $\alpha$ AND $\beta$ VARIABLE IN BANDWIDTH QOS

\begin{tabular}{|l|l|l|l|l|}
\hline Var & $\begin{array}{l}\text { pqij } \\
\text { increase } \boldsymbol{x} \\
\text { increase }\end{array}$ & $\begin{array}{l}\text { pqij increase } \\
\boldsymbol{x} \text { decrease }\end{array}$ & $\begin{array}{l}\text { Pqij decrease } \\
\boldsymbol{x} \\
\text { increase }\end{array}$ & $\begin{array}{l}\text { Pqij decrease } \\
\boldsymbol{x} \\
\text { decrease }\end{array}$ \\
\hline PQ11 & 8.467110 & 8.458654 & 0.2214369 & 0.2214369 \\
\hline PQ21 & 7.902642 & 7.894743 & 0.2066745 & 0.2066745 \\
\hline PQ31 & 40.07768 & 40.03763 & 1.048135 & 1.048135 \\
\hline X & 1 & 1 & 0 & 0 \\
\hline PB11 & 3.562910 & 3.562910 & 0.1288711 & 0.1288711 \\
\hline PB21 & 3.325383 & 3.325383 & 0.1202797 & 0.1202797 \\
\hline
\end{tabular}

\begin{tabular}{|c|c|c|c|c|}
\hline PB31 & 16.86444 & 16.86444 & 0.6099900 & 0.6099900 \\
\hline PR11 & 0.5 & 0.5 & 0.5 & 0.5 \\
\hline PR21 & 0.6 & 0.6 & 0.6 & 0.6 \\
\hline PR31 & 0.7 & 0.7 & 0.7 & 0.7 \\
\hline a11 & 0.15 & 0.15 & 0.15 & 0.15 \\
\hline a21 & 0.14 & 0.14 & 0.14 & 0.14 \\
\hline a31 & 0.71 & 0.71 & 0.71 & 0.71 \\
\hline $\mathbf{L} x$ & 2.375273 & 2.375273 & 1.718282 & 1.71828 \\
\hline$T \mathrm{i}$ & 1000 & 1000 & 50 & 50 \\
\hline$\alpha$ & 1 & 1 & 1 & 1 \\
\hline B & 1.07 & 1.07 & 0.8 & 0.8 \\
\hline$\beta 1$ & 0.5 & 0.5 & 0.5 & 0.5 \\
\hline$\beta 2$ & 0.5 & 0.5 & 0.5 & 0.5 \\
\hline$\beta 3$ & 0.5 & 0.5 & 0.5 & 0.5 \\
\hline I1 & 0.2983710 & 0.2983710 & 0.2983710 & 0.2983710 \\
\hline $\mathrm{I} 2$ & 0.2983710 & 0.2983710 & 0.2983710 & 0.2983710 \\
\hline I3 & 0.2983710 & 0.2983710 & 0.2983710 & 0.2983710 \\
\hline$\alpha 1$ & 1 & 1 & 1 & 1 \\
\hline$\alpha 2$ & 1 & 1 & 1 & 1 \\
\hline$\alpha 3$ & 1 & 1 & 1 & 1 \\
\hline L11 & 0,3 & 0.3 & 0.3 & 0.3 \\
\hline L21 & 0.33 & 0.33 & 0.33 & 0.33 \\
\hline L31 & 0.37 & 0.37 & 0.37 & 0.37 \\
\hline R11 & 0.00007 & 0.00007 & 0.00007 & 0.00007 \\
\hline R21 & 0.0006 & 0.0006 & 0.0006 & 0.0006 \\
\hline R31 & 0.005 & 0.005 & 0.005 & 0.005 \\
\hline
\end{tabular}

- $\alpha$ variable and $\beta$ constants in bandwidth Qos

Based on the objective function (67) and the equations from (2)-(32), (34)-(42), (54)- (56), and additional constraints (68) and (69). The optimal solution is summarized in Tables XI and XII for each case of the bandwidth features. We note from Table XI that the first case achieved the best result; it needs to get the results 14 iterations and the value of the memory used is 45.

From Table XII we notice that the values of the variables in the first and second cases are close, while in the 3 and 4 the results are identical. The first case gives the best results for the values of the variables. By comparing the optimal solution between the original model in Table $\mathrm{X}$ and the modified models in Table XI, we see that our model outperforms the previous model by 101.453.

- Comparison of optimal solutions between modified model [23], [17], and [22].

In this section, we compare the three models that used the bandwidth attribute in a single-link wireless network.

By comparing the results, we notice that our model [13] is better as it reaches the best profit (794.134) the results showed 
in Table XV. While in the model [17] , the best solution was $(692,681)$ as showed in Table XIV. In the model [22], the best profit was 32.68 as shed in Table XIII.

TABLE X. OPTIMAL SOLUTION FOR ORIGINAL MODELS FOR $a$ VARIABLE AND $\beta$ CONSTANT IN BANDWIDTH QOS

\begin{tabular}{|l|l|l|l|l|}
\hline Var & $\begin{array}{l}\text { pqij } \\
\text { increase } \boldsymbol{x} \\
\text { increase }\end{array}$ & $\begin{array}{l}\text { pqij } \\
\text { increase } \\
\boldsymbol{x} \text { decrease }\end{array}$ & $\begin{array}{l}\text { Pqij } \\
\text { decrease } \boldsymbol{x} \\
\text { increase }\end{array}$ & $\begin{array}{l}\text { Pqij } \\
\text { decrease } \boldsymbol{x} \\
\text { decrease }\end{array}$ \\
\hline Model Class & INLP & INLP & INLP & INLP \\
\hline State & Local Opt & Local Opt & Local Opt & Local Opt \\
\hline Objective & 692.681 & 692.625 & 634.758 & 634.758 \\
\hline Infeasibility & 0 & 0 & 0 & 0 \\
\hline Iter & 13 & 13 & 14 & 14 \\
\hline GMU & $35 \mathrm{~K}$ & $35 \mathrm{~K}$ & $35 \mathrm{~K}$ & $35 \mathrm{~K}$ \\
\hline ER & $0 \mathrm{~s}$ & $0 \mathrm{~s}$ & $0 \mathrm{~s}$ & $0 \mathrm{~s}$ \\
\hline
\end{tabular}

TABLE XI. OPTIMAL SOlUtIONS FOR MODELS FOR $\alpha$ VARIABLE AND $\beta$ CONSTANTS IN BANDWIDTH QOS

\begin{tabular}{|l|l|l|l|l|}
\hline Var & $\begin{array}{l}\text { pqij } \\
\text { increase } \boldsymbol{x} \\
\text { increase }\end{array}$ & $\begin{array}{l}\text { pqij } \\
\text { increase } \mathbf{x} \\
\text { decrease }\end{array}$ & $\begin{array}{l}\text { Pqij } \\
\text { decrease } \boldsymbol{x} \\
\text { increase }\end{array}$ & $\begin{array}{l}\text { Pqij } \\
\text { decrease } \boldsymbol{x} \\
\text { decrease }\end{array}$ \\
\hline $\begin{array}{l}\text { Model } \\
\text { Class }\end{array}$ & NLP & NLP & NLP & NLP \\
\hline State & Local Opt & Local Opt & Local Opt & Local Opt \\
\hline Objective & 794.130 & 794.076 & 736.211 & 736.211 \\
\hline Infeasibility & 0 & 0 & 0 & 0 \\
\hline Iter & 14 & 14 & 14 & 14 \\
\hline GMU & 45 & 45 & 43 & 43 \\
\hline ER & 0 & 0 & 0 & 0 \\
\hline
\end{tabular}

TABLE XII. VARIABLE VALUES FOR MODELS FOR $\alpha$ VARIABLE AND $\beta$ CONSTANTS IN BANDWIDTH QOS

\begin{tabular}{|l|l|l|l|l|}
\hline Var & $\begin{array}{l}\text { pqij } \\
\text { increase } \boldsymbol{x} \\
\text { increase }\end{array}$ & $\begin{array}{l}\text { pqij } \\
\text { increase } \\
\boldsymbol{x} \text { decrease }\end{array}$ & $\begin{array}{l}\text { Pqij decrease } \\
\boldsymbol{x} \\
\text { increase }\end{array}$ & $\begin{array}{l}\text { Pqij decrease } \\
\boldsymbol{x} \\
\text { decrease }\end{array}$ \\
\hline PQ11 & 8.467110 & 8.458654 & 0.2214369 & 0.2214369 \\
\hline PQ21 & 7.902642 & 7.894743 & 0.2066745 & 0.2066745 \\
\hline PQ31 & 40.07768 & 40.03763 & 1.048135 & 1.048135 \\
\hline X & 1 & 1 & 0 & 0 \\
\hline PB11 & 3.562910 & 3.562910 & 0.1288711 & 0.1288711 \\
\hline PB21 & 3.325383 & 3.325383 & 0.1202797 & 0.1202797 \\
\hline PB31 & 16.86444 & 16.86444 & 0.6099900 & 0.6099900 \\
\hline PR11 & 0.5 & 0.5 & 0.5 & 0.5 \\
\hline PR21 & 0.6 & 0.6 & 0.6 & 0.6 \\
\hline PR31 & 0.7 & 0.7 & 0.7 & 0.7 \\
\hline a11 & 0.15 & 0.15 & 0.15 & 0.15 \\
\hline a21 & 0.14 & 0.14 & 0.14 & 0.14 \\
\hline a31 & 0.71 & 0.71 & 0.71 & 0.71 \\
\hline
\end{tabular}

\begin{tabular}{|l|l|l|l|l|}
\hline $\mathbf{L} \boldsymbol{x}$ & 2.375273 & 2.375273 & 1.718282 & 1.71828 \\
\hline $\mathbf{T 1}$ & 1000 & 1000 & 50 & 50 \\
\hline $\mathbf{a}$ & 1 & 1 & 1 & 1 \\
\hline $\mathbf{B}$ & 1.07 & 1.07 & 0.8 & 0.8 \\
\hline $\boldsymbol{\beta} \mathbf{1}$ & 0.5 & 0.5 & 0.5 & 0.5 \\
\hline $\boldsymbol{\beta} \mathbf{2}$ & 0.5 & 0.5 & 0.5 & 0.5 \\
\hline $\boldsymbol{\beta} 3$ & 0.5 & 0.5 & 0.5 & 0.5 \\
\hline $\mathbf{I} 1$ & 0.2983710 & 0.2983710 & 0.2983710 & 0.2983710 \\
\hline $\mathbf{I}$ & 0.2983710 & 0.2983710 & 0.2983710 & 0.2983710 \\
\hline $\mathbf{I 3}$ & 0.2983710 & 0.2983710 & 0.2983710 & 0.2983710 \\
\hline $\boldsymbol{\alpha} \mathbf{1}$ & 1 & 1 & 1 & 1 \\
\hline $\boldsymbol{\alpha} 2$ & 1 & 1 & 1 & 1 \\
\hline $\boldsymbol{\alpha} 3$ & 1 & 1 & 1 & 1 \\
\hline $\boldsymbol{\Lambda} 11$ & 0,3 & 0.3 & 0.3 & 0.3 \\
\hline $\mathbf{\Lambda 2 1}$ & 0.33 & 0.33 & 0.33 & 0.33 \\
\hline $\boldsymbol{\Lambda} 31$ & 0.37 & 0.37 & 0.37 & 0.37 \\
\hline $\mathbf{P 1 1}$ & 0.00007 & 0.00007 & 0.00007 & 0.00007 \\
\hline $\mathbf{R 2 1}$ & 0.0006 & 0.0006 & 0.0006 & 0.0006 \\
\hline $\mathbf{R 3 1}$ & 0.005 & 0.005 & 0.005 & 0.005 \\
\hline
\end{tabular}

TABLE XIII. OPTIMAL SOLUTION OF ORIFGINAL MODELS OF WIRELESS INTERNET PRICING SCHEME ON BANDWIDTH QOS ATTRIBUTE [22]

\begin{tabular}{|l|l|l|l|l|}
\hline Var & $\begin{array}{l}\text { pqij } \\
\text { increase } \boldsymbol{x} \\
\text { increase }\end{array}$ & $\begin{array}{l}\text { pqij } \\
\text { increase } \\
\boldsymbol{x} \text { decrease }\end{array}$ & $\begin{array}{l}\text { Pqij } \\
\text { decrease } \boldsymbol{x} \\
\text { increase }\end{array}$ & $\begin{array}{l}\text { Pqij } \\
\text { decrease } \boldsymbol{x} \\
\text { decrease }\end{array}$ \\
\hline Model Class & NLP & NLP & NLP & NLP \\
\hline State & Local Opt & Local Opt & Local Opt & Local Opt \\
\hline Objective & 32.68 & 32.68 & 1.816 & 1.816 \\
\hline Infeasibility & 0 & 0 & $1.3 \times 10^{-17}$ & $1.3 \times 10^{-17}$ \\
\hline Iter & 11 & 11 & 11 & 11 \\
\hline GMU & $24 \mathrm{k}$ & $25 \mathrm{k}$ & $25 \mathrm{k}$ & $25 \mathrm{k}$ \\
\hline ER & 0 & 0 & 0 & 0 \\
\hline
\end{tabular}

TABLE XIV. OPTIMAL SOLUTION MOdELS OF WiRELESS INTERNET PRICING SCHEME ON BANDWIDTH QOS ATTRIBUTE [17]

\begin{tabular}{|l|l|l|l|l|}
\hline Var & $\begin{array}{l}\boldsymbol{\alpha} \text { and } \boldsymbol{\beta} \\
\text { constant }\end{array}$ & $\begin{array}{l}\boldsymbol{\alpha} \text { constant } \\
\text { and } \boldsymbol{\beta} \\
\text { variable }\end{array}$ & $\begin{array}{l}\boldsymbol{\alpha} \text { and } \boldsymbol{\beta} \\
\text { variable }\end{array}$ & $\begin{array}{l}\boldsymbol{\alpha} \text { variable } \\
\text { and } \boldsymbol{\beta} \\
\text { constant }\end{array}$ \\
\hline Model Class & INLP & INLP & INLP & INLP \\
\hline State & Local Opt & Local Opt & Local Opt & Local Opt \\
\hline Objective & 125.681 & 125.681 & 692.625 & 692.681 \\
\hline Infeasibility & 0 & 0 & 0 & 0 \\
\hline Iter & 13 & 13 & 13 & 13 \\
\hline GMU & $32 \mathrm{~K}$ & $32 \mathrm{~K}$ & $35 \mathrm{~K}$ & $35 \mathrm{~K}$ \\
\hline ER & 0 & 0 & 0 & 0 \\
\hline
\end{tabular}


TABLE XV. OPTIMAL SOLUTION OF MODIFIED MODEL OF WIRELESS INTERNET PRICING SCHEME ON BANDWIDTH QOS ATTRIBUTE [13]

\begin{tabular}{|l|l|l|l|l|}
\hline Var & $\begin{array}{l}\boldsymbol{\alpha} \text { and } \boldsymbol{\beta} \\
\text { constant }\end{array}$ & $\begin{array}{l}\boldsymbol{\alpha} \text { constant } \\
\text { and } \boldsymbol{\beta} \\
\text { variable }\end{array}$ & $\begin{array}{l}\boldsymbol{\alpha} \text { and } \boldsymbol{\beta} \\
\text { variable }\end{array}$ & $\begin{array}{l}\boldsymbol{\alpha} \text { variable } \\
\text { and } \boldsymbol{\beta} \\
\text { constant }\end{array}$ \\
\hline Model Class & NLP & NLP & NLP & NLP \\
\hline State & Local Opt & Local Opt & Local Opt & Local Opt \\
\hline Objet & 791.567 & 791.434 & 794.120 & 794.134 \\
\hline Infeasibility & 0 & 0 & 0 & 0 \\
\hline Iterations & 14 & 14 & 14 & 14 \\
\hline GMU & $44 \mathrm{k}$ & $44 \mathrm{k}$ & $44 \mathrm{k}$ & $44 \mathrm{k}$ \\
\hline ER & $0 \mathrm{~s}$ & $0 \mathrm{~s}$ & $0 \mathrm{~s}$ & $0 \mathrm{~s}$ \\
\hline
\end{tabular}

\section{CONCLUSION AND FUtURE WORK}

The basic price of the service has a major role in increasing the profit when it is variable, even though the quality of the service is constant, and this is proven by the results we have reached through the comparisons shown in the previous tables. In addition, an increase in the cost of service quality, and a variance in service quality categories, which will be reflected in an increase in service cost. In our improved model, we see that the best result is 794.134, which is in the case that the basic price $(\alpha)$ is variable and the premium quality $(\beta)$ is constant. For more future studies, it is possible to apply other features of the model and compare the various features to get the best scheme in addition to addressing the topic in terms of multi-links.

\section{ACKNOWLEDGMENT}

The research leading to this paper was financially supported by the Ministry of Higher Education Malaysia for support through Fundamental Research Grant Scheme 2020, Research Code: USIM-FRGS-FKAB-055002/53619.

\section{REFERENCES}

[1] E.-I. Apăvăloaie, "The impact of the internet on the business environment," Procedia Econ. Financ., vol. 15, pp. 951-958, 2014.

[2] N.Husein, A.Rahman, and D.Dahnil, "Evaluation of LoRa-based Air Pollution Monitoring System," Evaluation, vol. 10, no. 7, 2019.

[3] J. Byun and S. Chatterjee, "A strategic pricing for quality of service (QoS) network business," AMCIS 2004 Proc., p. 306, 2004.

[4] C. A. Martínez, D. A. L. Sarmiento, J. J. R. Ochoa, and R. D. G. Tovar, "Performance assessment of diffserv and intserv services in qos on an academic network using ns2," Tecciencia, vol. 7, no. 14, pp. 65-75, 2013.

[5] Indrawati, Irmeilyana, Puspita, F. M., \& Sanjaya, O. (2015). Internet pricing on bandwidth function diminished with increasing bandwidth utility function. TELKOMNIKA, 13(1), 299-304

[6] Puspita, F. M., Seman, K., Taib, B. M., \& Abdullah, I. (2017). The Comparison Of Internet Pricing Scheme In Multi Link Bottleneck Multi Service Network. Paper presented at the 6th International Conference on Computing and Informatics 2017 (ICOCI2017). Universiti Utara Malaysia, Sepang, Malaysia.
[7] G. Kesidis, A. Das, and G. de Veciana, "On flat-rate and usage-based pricing for tiered commodity internet services," in 2008 42nd Annual Conference on Information Sciences and Systems, 2008, pp. 304-308.

[8] F. M. Puspita, E. Yuliza, W. Herlina, Y. Yunita, and R. Rohania, "Improved Multi Service-Reverse Charging Models for the Multi Link Internet wireless Using QOS Bit Error Rate QoS Attribute," Sci. Technol. Indones., vol. 5, no. 1, pp. 6-13, 2020.

[9] F. M. Puspita, W. Herlina, S. Anggraini, B. Arisha, and Y. Yunita, "Improved internet wireless reverse charging models under multi link service network by end-to-end delay QoS attribute," in 2019 International Seminar on Research of Information Technology and Intelligent Systems (ISRITI), 2019, pp. 182-187.

[10] R. Sitepu, F. M. Puspita, A. N. Pratiwi, and I. P. Novyasti, "Utility Function-based Pricing Strategies in Maximizing the Information Service Provider's Revenue with Marginal and Monitoring Costs.," Int. J. Electr. Comput. Eng., vol. 7, no. 2, 2017.

[11] C. Gu, S. Zhuang, and Y. Sun, "Pricing Incentive Mechanism based on Multi-stages Traffic Classification Methodology for QoS-enabled Networks," J. Networks, vol. 6, no. 1, p. 163, 2011.

[12] P. Loiseau, G. Schwartz, J. Musacchio, and S. Amin, "Incentive schemes for internet congestion management: Raffles versus time-of-day pricing," in 2011 49th Annual Allerton Conference on Communication, Control, and Computing (Allerton), 2011, pp. 103-110.

[13] M. S. N.Hussein, K.Seman, F.Puspita, K.Abdulrahim, "Improved Model of Internet Pricing Incentive Mechanism based on Multi bottleneck Links in Multi QoS Networks," 2021.

[14] D. Ros and B. Tuffin, "A mathematical model of the Paris metro pricing scheme for charging packet networks," Comput. Networks, vol. 46, no. 1, pp. 73-85, 2004.

[15] S. Wu, P. Y. Chen, and G. Anandalingam, "Optimal pricing scheme for Information Services," Univ. Pennsylvania Philadelphia, 2002.

[16] F. M. Puspita and M. Oktaryna, "Improved bundle pricing model on wireless internet pricing scheme in serving multiple qos network based on quasi-linear utility function," in 2017 International Conference on Electrical Engineering and Computer Science (ICECOS), 2017, pp. 3843.

[17] Irmeilyana, Puspita, F. M., Indrawati, Agustin, R. T., \& Ulfa, M. (2017). Wireless single link pricing scheme under multi service network with bandwidth QOS attribute. ARPN Journal of Engineering and Applied Sciences. , 12(12).

[18] I. Irmeilyana, F. M. Puspita, I. Indrawati, and T. A. Rahayu, "Bit Error Rate (BER) QoS Attribute in Solving Wireless Pricing Scheme on Single Link Multi Service Network,” Int. J. Electr. Comput. Eng., vol. 8, no. 1, p. 236, 2018.

[19] Irmeilyana, Puspita, F. M., \& Husniah, I. (2016). Optimization of Wireless Internet Pricing Scheme in Serving Multi QoS Network Using Various QoS Attributes. TELKOMNIKA, Telecommunication, Computing, Electronics and Control, 14(1).

[20] S. Sain and S. Herpers, "Profit maximization in multi service networks-an optimization model.," in ECIS, 2003, pp. 1653-1669.

[21] I. Indrawati, I. Irmeilyana, F. M. Puspita, and M. P. Lestari, "CobbDouglass Utility Function in Optimizing the Internet Pricing Scheme Model," TELKOMNIKA (Telecommunication Comput. Electron. Control., vol. 12, no. 1, pp. 227-240, 2014.

[22] E. Wallenius, T. Hpmhihinen, I. P. M. Networks, and M. I. Technology, "PRICMG MODEL FOR 3G/4G NETWORKS," no. 1, pp. 187-191, 2002.

[23] N.Hussein, K.Seman, F.Puspita, K.Abdulrahim,M.Saharim "Improved Incentive Pricing Wireless Multi-Service Single Link With Bandwidth Attribute,” Int. J. Adv. Comput. Sci. Appl., vol. 12 No 7 Ju, 2021. 